\title{
Indirect Network Effects and Adoption Externalities
}

\author{
JEFFREY CHURCH * \\ Department of Economics, University of Calgary \\ NEIL GANDAL \\ Department of Public Policy, Tel Aviv University and CEPR \\ DAVID KRAUSE \\ Economic Analysis, Bell Canada
}

\begin{abstract}
Can indirect network effects lead to adoption externalities? If so, when? We show that in markets where consumption benefits arise from hardware/software systems, adoption externalities will occur when there are (i) increasing returns to scale in the production of software, (ii) free entry in software, and (iii) consumers have a preference for software variety. The private benefit of the marginal hardware purchaser is less than the social benefit since the marginal hardware purchaser does not internalize the welfare improving response of the software industry, particularly the increase in software variety, on inframarginal purchasers when the market for hardware expands.
\end{abstract}

\section{Introduction}

A network effect exists if consumption benefits depend positively on the total number of consumers who purchase compatible products. ${ }^{1}$ Katz and Shapiro (1985) distinguished between direct and indirect network effects. A direct effect arises when there is "a direct physical effect of the number of purchasers on the quality of the product" (p.424). Katz and Shapiro (1994) term networks with a direct physical effect "communication networks", and (not surprisingly) the canonical examples are communication technologies, such as telephone and email networks, as well as facsimile standards, where it is intuitive that the value of joining a network depends on the number of other consumers who join by adopting the same, or a compatible, technology.

When the network effect is indirect, consumption benefits do not depend directly on the size of the network (the total number of consumers who purchase compatible products)

\footnotetext{
* Contact Author. Department of Economics, University of Calgary, Calgary, Alberta, Canada, T2N 1N4. Email: jrchurch@ucalgary.ca We are grateful to the editor, Julian Wright, and to an anonymous referee for comments and suggestions that significantly improved the paper. Oz Shy, Guofu Tan, Curtis Eaton, Ken McKenzie, and Tom Cottrell provided helpful comments on earlier versions.

${ }^{1}$ The seminal modern contributions on network effects are a series of papers by Farrell and Saloner (1985, 1986a, 1986b) and Katz and Shapiro (1985, 1986). See Liebowitz and Margolis (2002) for a discussion of historical antecedents.
} 
per se. Rather, individuals care about the decisions of others because of their effects on the incentive for the provision of complementary products. Users of Macintosh computers are better off the greater the number of consumers who purchase Macs because the larger the number of Mac users, the greater the demand for compatible software, which if matched by an appropriate supply response - entry by software firms - will lead to lower prices and/or a greater variety of software, which makes all Mac users better off. This hardware/software paradigm applies to many markets, including most consumer electronic technologies, for example, video-cassette recorders, televisions, and audio technologies. However, it is not restricted to consumer electronics: other examples include natural gas fuelled automobiles (hardware) and natural gas filling stations (software); yellow pages (hardware) and listings (software); ATM/ABM cards (hardware) and compatible teller machines (software). Katz and Shapiro (1994) suggest that hardware/software systems can be viewed as "virtual networks" which have similar properties as direct networks. ${ }^{2}$

In the case of direct network effects, it is relatively uncontroversial that they can give rise to a network, or adoption, externality. Individuals, when they join a network characterized by direct network effects, do so on the basis of their private benefits and do not take into account that others on the network are also made better off by their decision to join. There has, however, been considerable disagreement in the literature over whether indirect network effects give rise to network externalities. See, for example, Liebowitz and Margolis (1994, 1995, 1998, 2002).

The objective of this paper is to determine the conditions under which indirect network effects give rise to real (adoption) externalities. We show that the critical requirements for indirect network effects to give rise to an adoption externality in hardware/software markets are three-fold: (i) increasing returns to scale in the production of software; (ii) free-entry into software; and (iii) consumer preferences for software variety. Under these circumstances, we demonstrate using a simple model, the existence of a positive adoption externality in a setting where consumption benefits arise from consuming systems composed of hardware and software and where the consumption benefits of hardware are increasing in the variety of compatible software. The marginal adopter does not take into account the benefits that accrue to inframarginal adopters from the response of the software industry to an increase in hardware sales. When there are increasing returns to scale and free-entry into the production of differentiated software, the key response to an increase in hardware sales is an increase in software variety which benefits inframarginal consumers.

The inefficiency we identify arises because the market coverage of the hardware good is endogenous. Since the marginal consumer only considers their private benefit, there exists an externality and the size of the hardware good in the market equilibrium is less than the social optimal size of the hardware market. The inefficiency - which imposes a social cost - arises because there are too few software varieties in the market equilibrium.

It is the increase in the variety of software that gives rise to an adoption externality: in general, the "network benefit effect" to inframarginal consumers can be broken down into a (i) variety (of software) effect and a (ii) competitive effect, which arises from lower prices of software from an increase in the number of software firms. The software price falls when the number of varieties in the market increases in our model and total surplus goes up as competition increases. This is not the only reason for the welfare of consumers

\footnotetext{
${ }^{2}$ See Katz and Shapiro (1985, 1994); Farrell and Saloner (1985); Chou and Shy (1990); and Church and Gandal (1992a, 1992b, 1993).
} 
to rise from a larger network. The variety effect arises because consumers have more options for their hardware. The relative magnitude of these effects is, of course, an empirical issue. In the appendix, we use a CES utility function ${ }^{3}$ to illustrate that the network benefit effect (from the internalization of the adoption externality) exists even in a setting in which the price of software does not depend on the number of software firms in the market. In such a case, the only component of the network benefit is the variety effect.

The variety effects which inframarginal consumers benefit from when there are indirect effects, we argue, are identical to the manner in which they benefit from a larger installed base when there are direct effects. This benefit arises from the ability to create new systems of complementary products. Network externalities that arise in settings with indirect network effects have the same microfoundations, in part, as network externalities that rise in settings with direct network effects.

Using a model that examines the social and private incentives to achieve standardization, Clements (2004) finds that a setting with direct network effects has different effects than a setting with indirect network effects. This differs from much of the literature, which finds that models of direct network effects give results qualitatively similar to those with models of indirect network effects. For example, both Farrell and Saloner (1986a) (a model of direct network effects) and Chou and Shy (1990) and Church and Gandal (1992a) (models of indirect network effects) find that market forces result in suboptimal standardization, that is, left alone the market may fail to achieve standardization when standardization is socially desirable. Clements finds the opposite. Clements may obtain a different result because in his setting, consumers consume only a single variety. In most of the literature in settings with indirect network effects, consumers have a taste for variety. The taste for variety is one of the key factors we argue is required for indirect network effects to lead to (just as in the case of direct network effects) adoption externalities.

A recent literature on two-sided markets addresses similar issues to those examined in the earlier literature on indirect network effects. Pioneers of the analysis of two-sided markets include Caillaud and Jullien (2003), Rochet and Tirole (2003), and Armstrong (2004). ${ }^{4}$ Two-sided markets involve a platform that must attract different groups to different sides of the platform. A typical two-sided market has both consumers and product suppliers: the platform owner in the middle tries to attract both groups. A video game console is a classic example; in order to succeed, the producer of a video game console must attract both consumers (who value the variety of games that can be played on the console), as well as software firms (who value the number of consumers that adopt the console). This setting seems quite similar to the literature on indirect network effects. Hagiu (2006, p.4) clarifies the relationship:

"Finally, our paper is related to the literature on indirect network effects, especially Church and Gandal (1992a) and Church, Gandal, and Krause (2003). Both papers study two-sided technology (or platform) adoption, however in both models, the platform is assumed to be entirely passive, that is, there is no strategic pricing on either side of the market. This is equivalent to an open platform in our model."

By "no strategic pricing on either side of the market," Hagiu means that the hardware firm (or platform) in Church and Gandal (1992) and our model does not formally enter into agreements with either consumers or software firms. Thus, two-sided markets with open

\footnotetext{
${ }^{3}$ The CES utility function was first used to model variety by Spence (1976) and Dixit and Stiglitz (1977).

${ }^{4}$ See Rosen (2005) for a recent survey.
} 
platforms are equivalent to a setting with indirect network effects when the hardware firm (platform) is not strategic. Hagiu's work (2006) is the most closely related to our model, but his focus is on comparing the relative efficiency of a monopoly-controlled platform (where the hardware firm sets prices for both software firms and consumers) to an open platform, with a focus on how the monopolist can use the two prices to internalize indirect network externalities. Our objective is to determine when these network effects are externalities in the absence of internalization.

Section 2 explains why the microfoundations of direct and indirect network effects are similar, and in doing so justifies the assumption that consumers are likely to have a preference for variety. The assumptions of our formal model are set out in Section $3 .^{5}$ In Section 4, we find the market equilibrium and in Section 5 we derive the efficient allocation. In Section 6, we demonstrate the inefficiency of the market equilibrium by showing that the equilibrium market network size is smaller than the socially optimal size. Section 7 offers a brief conclusion.

\section{Microfoundations of network benefits}

Though it seems intuitively obvious that communications networks give rise to network benefits and an adoption externality, in the context of the debate over whether and when indirect network effects give rise to a similar adoption externality it is illuminating to ask why. ${ }^{6}$ A more general perspective on both direct and indirect network effects recognizes that in both cases - what is perhaps the defining feature of a network - the products demanded are systems of components. Consumer demand is for a group of complementary products that, when combined or consumed together, provide value. It is often the case that the components by themselves have very little value.

A direct network consists of complements linked together to form a network. In this case, horizontal compatibility allows for interconnection of the product purchased by a consumer with that of others. The classic example is a local telephone exchange. Consumers gain access to the network when they subscribe by purchasing a link from their location to the local switch. For a call to be made requires that both the caller and the person called have such a link and value is created by combining the two links through the switch. In this case, the system that creates value is comprised of two complementary goods - the link of the caller and the link of the person called to the switch.

When an extra individual joins a network of $n$ individuals, in addition to the $n$ potential types of systems that are open to the new individual, the link of the new subscriber creates new systems for the $n$ inframarginal adopters or existing subscribers. The addition of a new individual to an $n$ individual network creates $n$ new systems - combinations of complements that can be connected by existing subscribers to create a new good. It is this

\footnotetext{
${ }^{5}$ The model presented here shares features with the work of Chou and Shy (1990) and Church and Gandal (1992a, 1992b, 1993). However, the existing literature is concerned with competition between different networks and a focus on whether the optimal technology was adopted in the market equilibrium, not whether adoption of a technology is sub-optimal and whether indirect network effects lead to network externalities.

${ }^{6}$ Our analysis here is based on, and extends, that of Economides and White (1998). Economides and White (1998) discuss both direct and indirect network effects, but they do not comment on if and when they give rise to network externalities. Nor do they model indirect network effects.
} 
creation of new systems for existing subscribers/adopters that is the benefit to existing subscribers of network expansion and the source of the network effect.

As in the direct network effects case, when there are indirect network effects consumers benefit from the adoption by others of compatible hardware because it allows them to consume a wider variety of systems. In this case, consumption benefits flow from creating systems consisting of one unit of hardware and one unit of software. The unit of hardware is typically compatible with many different varieties of software. If consumers value variety, then they will demand multiple systems, each involving one unit of hardware and a different variety of software. ${ }^{7}$ The advantage of more adopters of hardware to an existing subscriber arises if an increase in hardware adoption induces the production of more software varieties since existing adopters will then benefit from being able to create more two component systems, even if all prices are held constant. Adoption externalities that arise from both direct and indirect network effects have the same source - the creation of new goods for existing subscribers. ${ }^{8}$ An additional benefit may arise in the case of indirect network effects when the expansion in the number of software firms results in an increase in competition leading to lower prices.

\section{The model}

\subsection{Consumer preferences}

We assume that the preferences of consumers are defined over hardware, software, and a competitively supplied outside good. The tastes of consumers for hardware are distributed uniformly along a line of unit length, the population is normalized to one, and all consumers have income of $y$. The consumption of a hardware technology different from the most preferred type imposes a utility cost on the consumer that is proportional to the distance separating the consumer and the hardware technology consumed.

The utility of a consumer located distance $t$ from the hardware product consumed is

$$
U=M^{\beta}+x-k t,
$$

where $M$ is the number of software varieties consumed, $x$ is consumption of the competitively supplied numeraire good, and $k$ measures the degree of hardware

\footnotetext{
${ }^{7}$ It is a rare individual indeed who listens to only one compact disc on their stereo, uses only one application program on their PC, or plays only one video game on their video game console.

${ }^{8}$ This systems creation benefit shares some similarity to that found in the "mix and match" literature (Matutes and Regibeau, 1988; Economides, 1989) in that consumers benefit from an increase in the variety of components of a system. Typically in that literature firms produce the two components of a system. Compatibility enables consumers to build a system that is closer to their ideal since compatibility increases the number of available systems in a duopoly from two to four. However, our framework differs from that of the mix and match literature in a couple of important ways. Unlike the mix and match framework, we assume that consumers have a preference for consuming a variety of systems - not just one - and the number of systems is determined endogenously by free entry in software. It is these two features, free entry and a preference for variety, along with increasing returns to scale in software, that lead to adoption externalities when there are indirect network effects.
} 
differentiation. ${ }^{9}$ The network benefit function is $M^{\beta}$. We assume that demand for both a unit of hardware and any given variety of software is completely inelastic. ${ }^{10}$ We impose the restriction $0<\beta<1 / 2$. The restriction required for the marginal benefit of another variety to be declining is that $\beta<1$. A stronger restriction is required to insure that there may be an interior equilibrium, that is, less than universal adoption. ${ }^{11}$

Every consumer who purchases a unit of hardware maximizes their utility by choosing software and consumption of the outside good subject to the following budget constraint

$$
\sum_{j=1}^{M} \rho_{j}+x=y-p
$$

where $\rho_{j}$ is the price of a unit of software variety $j, y$ is the income of the consumer, $p$ is the price of the hardware technology, and $M$ is the number of software varieties purchased.

Each consumer optimally selects the number and varieties of software to consume by ranking the software varieties in ascending order by price. The marginal benefit of another software variety is $\beta M^{\beta-1}$. Ignoring the integer problem, the optimal number of software varieties $\hat{N}\left(\rho_{\hat{N}}\right)$ for a consumer who purchases hardware is implicitly defined by

$$
\rho_{\hat{N}}=\beta \hat{N}^{\beta-1},
$$

where $\rho_{\hat{N}}$ is the $\hat{N}^{t h}$ most expensive software variety. In other words, the consumer purchases one unit of the $\hat{N}^{\text {th }}$ lowest-priced varieties, where $\hat{N}$ is such that the marginal benefit of the $\hat{N}^{\text {th }}$ software product equals $\rho_{\hat{N}} \cdot{ }^{12}$

Indirect utility as a function of software prices and the hardware price is

$$
V=\left(\hat{N}\left(\rho_{\hat{N}}\right)\right)^{\beta}+y-p-\sum_{j=1}^{\hat{N}\left(\rho_{\hat{N}}\right)} \rho_{i}-k t .
$$

The marginal consumer is indifferent between only consuming the numeraire good and purchasing hardware. Setting (4) equal to $y$, the utility from consuming only the numeraire good, the size of the network is

\footnotetext{
${ }^{9}$ Since we restrict the distribution of consumer preferences to be on the unit interval, $t$ is restricted to the interval $0 \leq t \leq 1$

${ }^{10}$ Demand is not perfectly inelastic, since above a certain price consumers no longer purchase the product. However, up to that price demand is perfectly inelastic and henceforth demand will be referred to as being completely inelastic. Examples of different software varieties for personal computers are a spreadsheet, word processor, database, etc.

${ }^{11}$ In the concluding section, we discuss the implications for our results when consumers have stronger preferences for variety, that is, $1 / 2 \leq \beta<1$.

${ }^{12}$ We ignore the possibility that such an $\hat{N}$ might not exist. We show below that equilibrium pricing behaviour by software firms will ensure that it does.
} 


$$
t=\frac{\hat{N}^{\beta}-p-\sum_{j=1}^{\hat{N}} \rho_{j}}{k},
$$

where $0 \leq t \leq 1$. Equivalently, the size of the network is the demand function for hardware. The demand for hardware depends not only on the price of hardware, but also on the number and prices of compatible software varieties.

\subsection{Technology}

We assume that the competitive suppliers of hardware all offer a product located at one end of the unit interval. ${ }^{13}$ We also assume that there are constant returns to scale in the production of hardware. Let the constant unit cost of hardware be equal to $c$. Our assumption of competition in the provision of hardware means that the price of hardware will be equal to $c$. Without loss of generality, we set $c=0$.

We assume that the production of software is characterized by increasing returns to scale: the marginal production cost of a unit of variety is zero, but associated with each software variety is a fixed cost equal to $f .{ }^{14}$ Software firms are restricted to providing only a single software variety and there is free entry into the software industry.

\subsection{Timing}

We assume a simple two-stage game and solve for the subgame perfect Nash equilibrium (SPNE). In the second stage, the number of software varieties is fixed and there is price competition between software firms and, given the Nash equilibrium in software (and hardware) prices, consumers make their adoption decision. The assumption of competitive hardware means that the Nash equilibrium hardware price is simply its marginal cost. In the first stage, there is free-entry into software. The effect of subgame perfection is that software firms anticipate correctly the dependence of second period equilibrium prices, hardware adoption, and profits on the number of software varieties. ${ }^{15}$

\section{$4 \quad$ Market equilibrium}

\subsection{Nash equilibrium in software prices}

The determination of the Nash equilibrium in software prices in the second stage, when there are $N$ software firms, involves two steps: (i) finding equilibrium prices assuming that software firms believe that the size of the network, that is, hardware sales, is invariant to software pricing; and (ii) showing that software firms will, in fact price, as if the size of the

\footnotetext{
13 The assumption of competitive supply is made for two reasons. First it simplifies the analysis, second it eliminates a potential source of market failure - market power in hardware.

${ }^{14}$ Given that demand for a unit of hardware and each variety of software is completely inelastic for an individual consumer, the assumption of zero marginal cost in either hardware or software has no effect on the results. This assumption is made to simplify the presentation.

${ }^{15}$ We adopt a two-stage game for ease of presentation. The Nash equilibrium to a simple static game where pricing and entry by software firms occur simultaneously is identical to that of the SPNE in the two-stage game considered here.
} 
network is fixed, since a single software firm will not find it profitable to lower its price in order to induce more consumers to join the network by buying hardware.

\subsubsection{Step 1: Hardware sales invariant to software pricing}

Suppose that there are $N$ software firms which have each developed a single software variety and, contrary to the rules of the game, consumers have already purchased hardware so that the size of the network is fixed. Then, the Nash equilibrium software price will be

$$
\rho(N)=\beta N^{\beta-1}
$$

If the price of a variety of software exceeds $\beta N^{\beta-1}$ (its marginal benefit), consumers will not purchase it. A price less than $\beta N^{\beta-1}$ reduces profits since quantity is unchanged as the demand by a consumer for a variety of software is completely inelastic and the market size is assumed to be fixed.

A symmetric equilibrium software price given by (6) implies, from (5) and $p=c=0$, an equilibrium network size of

$$
t(N)=\frac{(1-\beta) N^{\beta}}{k}
$$

when there are $N$ software firms.

\subsubsection{Step 2: An individual software firm does not have an incentive to price to expand network size}

However, given the rules of the game, the size of the network is not fixed: from (5), it depends on the price of every software variety. While it is clear that no software firm will ever charge a price higher than (6) - since its sales would then be zero - we need to determine whether a software firm might find it profitable to unilaterally deviate from (6) and charge a lower price in order to induce more consumers to buy hardware and extend the network. The revenue for software firm $j$ is

$$
R_{j}=\rho_{j} t
$$

where $t$ is given by equation (5). The change in the revenue of firm $j$ given a change in the price of its software variety is

$$
\frac{\partial R_{j}}{\partial \rho_{j}}=t+\rho_{j} \frac{\partial t}{\partial \rho_{j}} .
$$

Decreasing the price of its software variety marginally will decrease its revenue by $t$, the loss in revenue on inframarginal units. A marginal reduction in $\rho_{j}$ increases the size of the network, and thus sales, by $\partial t / \partial \rho_{j}=1 / k$. An upper bound on the increase in revenue from marginal sales from a decrease in the software price is 


$$
\rho_{j}(N) \frac{\partial t}{\partial \rho_{j}}=\frac{\beta N^{\beta-1}}{k}
$$

It is an upper bound since it values marginal sales by the proposed Nash price, (6), and not $\rho_{j}$, the lower price.

Proposition 1 When $N>1$ and $\beta \leq 1 / 2$ the Nash equilibrium in software prices is given by (6), that is, $\rho(N)=\beta N^{\beta-1}$.

Proof. For $t<1$, the loss on inframarginal units from a price decrease is $t(N)=(1-\beta) N^{\beta} / k$, and the upper bound on the revenue from marginal sales from a price decrease is

$$
\rho_{j}(N) \frac{\partial t}{\partial \rho_{j}}=\frac{\beta N^{\beta-1}}{k}
$$

The decrease in revenue on the inframarginal units is greater than the increase in revenue from the marginal sales from a reduction in the software price $\rho_{j}(N)$ if

$$
\frac{(1-\beta) N^{\beta}}{k}-\frac{\beta N^{\beta-1}}{k}>0
$$

This is true when $N>1$ and $\beta \leq 1 / 2$. For $t=1$, a reduction in the price of software below (6) by firm $j$ reduces revenue on inframarginal units but does not increase quantity. Prices greater than (6) result in sales of zero since price exceeds marginal benefit for all consumers.

In equilibrium, each variety of software is priced such that consumers purchase one unit from each software firm and $\hat{N}=N$. The price of software exactly equals its marginal benefit and all consumers who purchase hardware consume one unit of each software product.

\subsection{Nash equilibrium in software variety}

In the first stage of the game, there is free entry into software. The equilibrium number of software firms (and thus varieties) will be determined by the free-entry condition of zero profits given the equilibrium software price (6).

The equilibrium profits of a software firm when there are $N$ software firms is

$$
\pi(N)=\rho(N) t(N)-f
$$

Substituting (6) into (12) and setting the result equal to zero implicitly defines the free entry number of software firms 


$$
\beta N^{\beta-1} t(N)=f
$$

The equilibrium network size, $t(N)$, is given by (7) provided $t \leq 1$. The free-entry equilibrium is defined by the simultaneous solution of (7) and (13). ${ }^{16}$ We can distinguish between an interior equilibrium where $1>t>0$ - in which only some consumers join the network - and universal adoption where $t=1$ and all consumers adopt the hardware. Whether the equilibrium involves universal adoption or not depends on the relationship between the extent of hardware differentiation and the value of software.

The effect of entry by another software firm (which supplies an additional variety of software) on equilibrium software profits is given by

$$
\frac{\partial \pi(N)}{\partial N}=\frac{\partial \rho(N)}{\partial N} t(N)+\rho(N) \frac{\partial t(N)}{\partial N} .
$$

The first term in (14) captures the competitive effect of additional entry: an additional competitor reduces equilibrium software prices. The second term captures the network effect: additional software makes purchasing hardware more attractive, hence extends the hardware market. If the second effect dominates, software firms will continue to enter the market until the market is covered, at which point the network effect is zero. ${ }^{17}$ The existence of an interior equilibrium requires that entry from an additional firm will reduce profits.

However, this is not sufficient for an interior equilibrium. It must also be the case that the number of software firms which enter in the interior equilibrium is less than the number required to induce every consumer to purchase hardware or join the market. This implies a restriction on $f$.

Proposition 2 If the willingness to pay for variety is sufficiently small, namely $0<\beta<1 / 2$, then:

(1) An Interior Equilibrium exists if

$$
\beta(1-\beta) / k>f>\beta\left(\frac{(1-\beta)}{k}\right)^{\left(\frac{1-\beta}{\beta}\right)}
$$

and the equilibrium network size $t_{m}$ and the number of software varieties $N_{m}$ are

\footnotetext{
${ }^{16}$ The Nash equilibrium to an alternative game in which pricing and entry by software firms occurs simultaneously would be found by solving the same two equations. In this case, $N$ in (7) would be the expected number of software varieties, which if consumers have rational expectations, is given by (13), and $t(N)$ in (13) is expected market size, which under rational expectations is given by (7).

${ }^{17}$ This terminology is consistent with the analysis and terminology used by Church and Gandal (1992a) in their analysis of the incentives of software firms to supply complementary products when there are competing hardware products/networks.
} 


$$
t_{m}=\left[\frac{(1-\beta)}{k}\right]^{\frac{1-\beta}{1-2 \beta}}\left[\frac{\beta}{f}\right]^{\frac{\beta}{1-2 \beta}}
$$

and

$$
N_{m}=\left[\frac{(1-\beta)}{k}\right]^{\frac{1}{1-2 \beta}}\left[\frac{\beta}{f}\right]^{\frac{1}{1-2 \beta}} .
$$

(2) Universal Adoption occurs when

$$
\beta\left(\frac{(1-\beta)}{k}\right)^{\left(\frac{1-\beta}{\beta}\right)}>f
$$

and the equilibrium network size and number of software varieties are

$$
t_{m}=\bar{t}=1
$$

and

$$
N_{m}=\bar{N}=\left(\frac{\beta}{f}\right)^{\left(\frac{1}{1-\beta}\right)} .
$$

Proof. Substituting in the equilibrium network size given by (7) and the equilibrium software price given by (6) into the expression for profits of a software firm (12) and simplifying yields

$$
\pi(N)=\beta N^{\beta-1}\left[\frac{(1-\beta) N^{\beta}}{k}\right]-f .
$$

The equilibrium number of software firms will exceed 1 (recall from Proposition 1 this condition is required for (6) to be the equilibrium software price) if $\pi(N=1)>0$ and this will be true when $\beta(1-\beta) / k>f$.

For the interior equilibrium number of software varieties, set (18) equal to zero and solve for $N$. For the equilibrium network size, insert the result into (7).

An interior equilibrium exists if: (i) the competitive effect dominates and (ii) $t_{m}<1$. The competitive effect dominates if $\partial \pi(N) / \partial N<0$. Differentiating (18) with respect to $N$ yields

$$
\frac{\partial \pi(N)}{\partial N}=-\beta(1-\beta)^{2}\left[\frac{N^{2 \beta-2}}{k}\right]+\beta^{2}(1-\beta)\left[\frac{N^{2 \beta-2}}{k}\right]
$$


which is negative when $\beta<1 / 2$.

Setting (7) equal to 1 , universal adoption occurs when there are $\bar{N}$ varieties of software

$$
\bar{N}=\left[\frac{k}{1-\beta}\right]^{\frac{1}{\beta}} .
$$

The equilibrium number of software varieties will be less than the number required for full market coverage provided $f$ is such that when $N=\bar{N}$, the profits of a software firm are negative

$$
\beta\left[\frac{k}{(1-\beta)}\right]^{\left(\frac{\beta-1}{\beta}\right)}-f<0 .
$$

This is true when

$$
f>\beta\left[\frac{(1-\beta)}{k}\right]^{\left(\frac{1-\beta}{\beta}\right)} .
$$

The free-entry number of software firms when there is universal adoption is found by setting $t=1$ in (13) and solving for $N$.

\section{Social optimum}

In this section, we derive the efficient network size. In the first-best allocation the social planner selects both network size $\left(t_{s}\right)$ and the number of software varieties $\left(N_{s}\right)$ to maximize welfare. In the second-best allocation, the social planner can only mandate adoption of the hardware technology and cannot determine directly the number of software varieties. In the second-best allocation, the social planner knows that for any $t_{s}$, the variety of software will be determined by the free-entry condition, (13).

\subsection{First-best allocation}

The objective function of the social planner is

$$
W^{*}=\int_{0}^{t_{s}}\left[N_{s}^{\beta}+\bar{x}-k t_{s}\right] d t_{s}+\int_{t_{s}}^{1} \hat{x} d t_{s}
$$

The first term of (23) is the direct utility of those consumers on the network and the second term in (23) is the utility of those not on the network, where $\bar{x}$ and $\hat{x}$ are consumption of the numeraire good by a consumer in each group. Since profits in both hardware and software will be zero, only the surplus of consumers is relevant. In the first- 
best allocation the social planner maximizes (23) subject to the following resource constraint

$$
f N_{s}+\int_{0}^{t_{s}} \bar{x} d t_{s}+\int_{t_{s}}^{1} \hat{x} d t_{s}=y
$$

Integrating (23) and (24) and then substituting in the resource constraint, the first-best allocation is defined by maximizing

$$
W^{*}=N_{s}^{\beta} t_{s}+y-\frac{k t_{s}^{2}}{2}-f N_{s}
$$

with respect to $t_{s}$ and $N_{s}$, that is, the extent of the network (hardware quantity) and software varieties.

The two first-order necessary conditions are

$$
\frac{\partial W^{*}}{\partial N_{s}}=\beta N_{s}^{(\beta-1)} t_{s}-f=0
$$

and

$$
\frac{\partial W^{*}}{\partial t_{s}}=N_{s}^{\beta}-k t_{s}=0
$$

The first term in (26) is the marginal social benefit of another software variety (the product of marginal utility and network size) and the second is the marginal social cost of another variety. The first term in (27) is the marginal social benefit to expanding the hardware network; the second term is the marginal social cost.

\subsection{Second-best allocation}

In the second-best allocation, the social planner can only determine the size of the hardware network and the number of software varieties is determined by free-entry. The constrained optimal market size maximizes

$$
W=\int_{0}^{t_{s}}\left[(1-\beta) N^{\beta}+y-k t_{s}\right] d t_{s}+\int_{t_{s}}^{1} y d t_{s}
$$

subject to

$$
\beta N^{\beta-1} t_{s}=f .
$$

The first term of (28) is the indirect utility of those consumers on the network and the second term in (28) is the indirect utility of those not on the network. Since profits in both hardware and software will be zero, only the surplus of consumers is relevant. The 
constraint is the free entry, zero-profit condition, which determines the number of software firms, hence the software variety for any $t_{s}$ chosen by the social planner.

Integrating (28) and substituting in the definition of $N$ from the constraint the secondbest allocation is defined by maximizing

$$
W=(1-\beta)\left(\frac{\beta t_{s}}{f}\right)^{\left(\frac{\beta}{1-\beta}\right)} t_{s}+y-\frac{k t_{s}^{2}}{2}
$$

with respect to $t_{s}$.

In this simple model, the first-best and second-best allocations are identical. To see this, observe that the constraint in the second-best problem (29) is identical to one of the first-order conditions in the first-best problem (26) and maximizing (30) with respect to $t_{s}$ gives the same first-order condition as (27): $N_{s}^{\beta}-k t_{s}=0$. As the two allocations are identical, henceforth we will consider only the second-best problem and refer to it as the efficient outcome.

The efficient outcome can either involve partial or universal adoption. Partial adoption, or an interior solution, to the social optimum requires that the marginal benefit of increasing $t_{s}$ be negative when $t_{s}=1$. If it is positive, then the efficient solution involves universal adoption, that is, $t_{s}=1$.

Proposition 3 If the willingness to pay for variety is sufficiently small, namely $0<\beta<1 / 2$, then:

\section{(1) Partial Adoption:}

If $f>\beta(1 / k)^{(1-\beta) / \beta}$ then the socially optimal network size and number of software varieties are

$$
t_{s}=\left[\frac{1}{k}\right]^{\frac{1-\beta}{1-2 \beta}}\left[\frac{\beta}{f}\right]^{\frac{\beta}{1-2 \beta}}
$$

and

$$
N_{s}=\left[\frac{1}{k}\right]^{\frac{1}{1-2 \beta}}\left[\frac{\beta}{f}\right]^{\frac{1}{1-2 \beta}} .
$$

(2) Universal Adoption:

If $\beta(1 / k)^{(1-\beta) / \beta} \geq f$ then the socially optimal network size and number of software varieties are

$$
t_{s}=1
$$

and 


$$
N_{s}=\left(\frac{\beta}{f}\right)^{\left(\frac{1}{1-\beta}\right)} .
$$

Proof. For the interior solution, integrate (28), substitute in the definition of $N$ from the free-entry constraint (29) and maximize with respect to $t_{s}$. An interior solution to the social optimum requires that the marginal benefit of increasing $t_{s}$ be negative when $t_{s}=1$. The marginal benefit of increasing $t_{s}$ is

$$
\frac{\partial W}{\partial t_{s}}=\left[\frac{\beta t_{s}}{f}\right]^{\left(\frac{\beta}{1-\beta}\right)}-k t_{s} .
$$

Given that $\beta<1 / 2$, this is negative at $t_{s}=1$ when $f>\beta(1 / k)^{(1-\beta) / \beta}$.

If $\beta<1 / 2$ and $f \leq \beta(1 / k)^{(1-\beta) / \beta}$, then the marginal benefit of increasing $t_{s}$ is positive at $t_{s}=1$ and the efficient solution is to maximize the size of the network. The optimal number of software varieties when there is universal adoption is found by substituting $t_{s}=1$ into (29) and solving for $N$.

\section{$6 \quad$ Market efficiency}

Proposition 4 When market adoption leads to full coverage, market adoption is efficient. When market adoption does not lead to full coverage, market adoption is inefficient. This inefficiency manifests itself in two ways: (i) The market network is smaller than the socially optimal network when the socially optimal network does not involve universal adoption; and (ii) The social optimum involves universal adoption, but adoption in the market equilibrium is only partial.

Proof. Follows directly from comparing Proposition 2 to Proposition 3.

Proposition 4 indicates that the "virtual networks" which exist in hardware/software industries are characterized by the same kind of inefficiency associated with physical networks. The inefficiency arises for the same reason: an adoption externality. The social planner considers not only the welfare of the marginal consumer, but also the effect that extending the hardware network will have on the supply of software, hence the welfare of inframarginal consumers. In the market equilibrium, marginal consumers consider only their private benefit when making their adoption decision.

To see this more clearly, observe that after integrating (28), the social planner's objective function is

$$
W=(1-\beta) N^{\beta} t_{s}-\frac{k t_{s}^{2}}{2}+y
$$


The derivative of (36) with respect to $t_{s}$ is

$$
\frac{d W}{d t_{s}}=(1-\beta)\left[\beta N^{\beta-1} \frac{d N}{d t_{s}} t_{s}+N^{\beta}\right]-k t_{s},
$$

where from the constraint the social planner recognizes the dependence of $N$ on $t_{s}$. If $d N / d t_{s}=0$, then setting (37) equal to zero and solving for $t_{s}$ would yield $t_{s}(N)=t_{m}(N)$, or equation (7). The reason that $t_{s}(N)>t_{m}(N)$ is because the social planner recognizes that $d N / d t_{s}>0$. Increasing the extent of hardware adoption will induce entry by additional software firms and a welfare increasing proliferation of software varieties.

The marginal external benefit of adoption is

$$
\beta(1-\beta) N^{\beta-1} \frac{d N}{d t_{s}} t_{s}
$$

This is the increase in software varieties from increasing hardware adoption multiplied by the product of the net marginal utility of another software variety and the size of the network. To see this, note that the net benefit (or indirect utility) of a consumer from consuming $N$ varieties at a price per variety of $\rho(N)$ is

$$
V(N)=N^{\beta}-\rho(N) N
$$

Differentiating this with respect to $N$ shows the two benefits to inframarginal adopters from extending the network

$$
\frac{d V}{d N}=\beta N^{(\beta-1)}-\frac{d \rho}{d N} N-\rho .
$$

The first term on the right-hand side in (40) is the variety benefit and the second term is the competitive effect (the decrease in price of software). The third term shows that to find the net benefit of an increase in $N$, the cost of the additional variety purchased must be deducted from the variety and competitive effect benefits.

In our model $\rho(N)=\beta N^{\beta-1}$ so (40) is

$$
\frac{d V}{d N}=\beta N^{(\beta-1)}+\beta(1-\beta) N^{(\beta-1)}-\beta N^{(\beta-1)} .
$$

This shows that the variety effect (first term) is larger than the competitive effect (second term). The ratio of the variety effect to the competitive effect is $1 /(1-\beta)$. The 
variety effect is larger than the price effect and the difference is increasing in $\beta$, the importance of software. ${ }^{18}$

Our objective is to determine the circumstances when indirect network effects give rise to a positive adoption, or network, externality. One way to confirm that the externality is real is to show that a tax and subsidy scheme that internalized the externality could, at least in theory, improve welfare. A social planner should be willing to subsidize network adoption in order to increase the number of software varieties, which benefits all adopters, not just the marginal adopter. Suppose that a subsidy of $s$ is offered to hardware adopters that is, the price of hardware is reduced by $s$ - and it is financed through a lump-sum tax. Then the demand for hardware (the network size) is no longer (7) but instead

$$
t(N, s)=\frac{(1-\beta) N^{\beta}+s}{k}
$$

reflecting that the price of hardware is zero and adopters receive a payment of $s$.

The free-entry condition, from (13), that determines the number of software varieties is

$$
\beta N^{\beta-1} t(N, s)=f
$$

Solving (42) and (43), the subsidy required to achieve any market length $t$ is

$$
s(t)=k t-(1-\beta) t^{\frac{\beta}{(1-\beta)}}\left[\frac{\beta}{f}\right]^{\frac{\beta}{(1-\beta)}} .
$$

The relevant $t$ for the social optimum is given by (31).

For instance, suppose that $k=2, \beta=0.25$, and $f=0.05$. Then $t_{m}=0.51$ and $N_{m}=3.52$. The efficient outcome is $t_{s}=0.79$ and $N_{s}=6.25$. The market equilibrium has a network size less than $65 \%$ of the efficient network size, with only just over $55 \%$ of the efficient software variety. An adoption subsidy of $s=0.40$ would result in $t_{m}=0.79$ and $N_{m}=6.25$. The increase in welfare from the subsidy is, using (36), almost $19 \%$.

\section{Conclusion}

Our analysis indicates that when market adoption leads to full coverage, there is no inefficiency. In this case, the market outcome and the social outcome are identical and, in particular, the number of software varieties is the same. This is similar to the findings of Spence (1976) and Dixit and Stiglitz (1977) on the optimality of monopolistic competition

\footnotetext{
${ }^{18}$ Interestingly enough, the net benefit to consumers of an increase in $N$ equals the competitive effect. This is because in our pricing game the price of a software variety equals its marginal utility. As a result, firms capture all of the benefit from the variety effect. In the Appendix, we present a model that assumes CES preferences over software. In that model, there is neither a price effect nor an expenditure effect: increases in $N$ neither lead to a reduction in the software price nor an increase in expenditure. Instead, there is only a variety effect, resulting in $t_{s}>t_{m}$ and $N_{s}>N_{m}$.
} 
with an outside good. The market and social optimum would be the same if the market coverage of hardware in the market equilibrium was the same as the socially optimal coverage: the number of software products and their prices in the market equilibrium would be the same as those in the constrained optimum.

Our inefficiency arises because the market coverage of the hardware good is endogenous. When the market equilibrium does not involve complete market coverage, then in our model, indirect network effects give rise to an adoption externality. ${ }^{19}$ The marginal consumer only considers their private benefit from adoption and the extent of coverage in the hardware market is less than optimal. The external benefit from adoption has two sources: a variety and a competition effect. It arises when expansion in the size of the hardware market results in an increase in software varieties, an increase that benefits all consumers. ${ }^{20}$

The critical requirements for indirect network effects to give rise to an adoption externality in hardware/software system markets are three-fold: (i) increasing returns to scale in the production of software; (ii) free-entry into software; and (iii) consumer preferences for software variety. To illustrate the role of (i), assume that there is constant returns to scale in the production of a software variety. Under these circumstances, the equilibrium number of software varieties and their price would be invariant to the number of consumers who purchase hardware. The effect of the marginal adopter is to simply increase sales of existing software varieties at existing prices, not the number of varieties. If there is not free-entry into software - requirement (ii) - then clearly an increase in the number of adopters does not lead to an increase in the number of software varieties or a competitive effect. Without a preference for software variety by consumers - requirement (iii) - the link from increased demand to an increase in supply of software varieties and increased utility for all consumers is broken. ${ }^{21}$

In our view, these three critical requirements apply to most examples suggested as illustrative of indirect network effects. By clarifying the circumstances under which indirect network effects give rise to adoption externalities, this paper provides the necessary foundation for the ongoing debate involving the broader concern of how public

\footnotetext{
${ }^{19}$ If the preference for software variety is too strong, which in our model corresponds to $1 / 2 \leq \beta<1$, then it is straightforward to demonstrate that the market equilibrium involves universal adoption or standardization. In these circumstances, the efficient outcome also involves standardization and, as when there is full coverage when $0<\beta<1 / 2$, there is not an inefficiency.

${ }^{20}$ The inefficiency of the market equilibrium in our model is not attributable to market power. The price of software is above marginal cost in order to ensure that software firms earn non-negative profits, but the price of software equals average cost. Given the number of software varieties in the market equilibrium, the price of software is efficient. The inefficiency arises because there are too few software varieties in the market equilibrium since the network size - extent of hardware adoption - is too small.

${ }^{21}$ Many industries have increasing returns to scale in the production of software and free entry into that industry. But industries vary as to the importance of variety. In the case of fly-fishing, for example, very few consumers who purchase a fishing pole (the hardware) will purchase more than just one or two books (the software) on how to fish. And the availability of books on fishing will not be a major determinant of the benefits from the fishing pole: some individuals who buy fishing poles will not buy any books on fishing. Hence, in such a setting, the value of additional software variety is quite small. On the other hand, consumers who purchase video game consoles or compact disc players are likely to purchase very large numbers of complementary varieties. In this case, the value of additional software variety is quite large and without complementary software the benefit from the compact disc player marginal, if not zero. Hence, we would say that the effect we describe is much more important in the latter two industries than in the fishing industry.
} 
policy should change - if at all - given the increasing importance of industries characterized by indirect network effects in the economy.

\section{$8 \quad$ References}

Armstrong, M. (2004) “Competition in Two-Sided Markets,” Mimeo, University College, London.

Caillaud, B. and Jullien, B. (2003) "Chicken and Egg: Competition among Intermediation Service Providers,” Rand Journal of Economics, 34: 309-328.

Chou, C. and O. Shy (1990) "Network Effects Without Network Externalities," International Journal of Industrial Organization, 8: 259-70.

Church, J. and N. Gandal (1992a) "Network Effects, Software Provision, and Standardization,” Journal of Industrial Economics, XL: 85-104.

Church, J. and N. Gandal (1992b) "Integration, Complementary Products and Variety" Journal of Economics and Management Strategy, 1: 651-75.

Church, J. and N. Gandal (1993) "Complementary Network Externalities and Technological Adoption,” International Journal of Industrial Organization, 11: 239-60.

Church, J. and N. Gandal (2000) "Systems Competition, Vertical Merger and Foreclosure,” Journal of Economics and Management Strategy, 9: 25-52.

Church, J., Gandal, N., and D. Krause (2003) "Indirect Network Effects and Adoption Externalities,” CEPR Discussion Paper DP3738.

Clements, M. (2004) "Direct and Indirect Network Effects: Are They Equivalent?" International Journal of Industrial Organization, 22: 633-645.

Dixit, A. and J. Stiglitz (1977) "Monopolistic Competition and Optimum Product Diversity,” American Economic Review, 67: 297-308.

Economides, N. (1989) "Desirability of Compatibility in the Absence of Network Externalities,” American Economic Review, 78: 108-121.

Economides, N. (1996) “The Economics of Networks," International Journal of Industrial Organization, 14: 673-701.

Economides, N. and L.J. White (1998) "One-Way Networks, Two-Way Networks, Compatibility, and Public Policy," in D. Gabel and D. Weiman (ed.), Opening Networks to Competition, Kluwer: Boston.

Farrell, J. and G. Saloner (1985) "Standardization, Compatibility, and Innovation,” RAND Journal of Economics, 16: 70-83. 
Farrell, J. and G. Saloner (1986a) "Standardization and Variety," Economics Letters, 20: 71-74.

Farrell, J. and G. Saloner (1986b) "Installed Base and Compatibility: Innovation, Production Preannouncements and Predation,” American Economic Review, 76: 940-55.

Hagiu, A. (2006) "Proprietary vs. Open Two Sided Platforms and Social Efficiency," Working Paper 06-12, AEI-Brookings Joint Center.

Katz, M. and C. Shapiro (1985) "Network Externalities, Competition and Compatibility," American Economic Review, 75: 424-40.

Katz, M. and C. Shapiro (1986) "Technology Adoption in the Presence of Network Externalities,” Journal of Political Economy, 94: 822-41.

Katz, M. and C. Shapiro (1994) "Systems Competition and Network Effects," The Journal of Economic Perspectives, 8: 93-115.

Liebowitz, S.J. and S.E. Margolis (1994) "Network Externality: An Uncommon Tragedy," The Journal of Economic Perspectives, 8: 133-50.

Liebowitz, S.J. and S.E. Margolis (1995) “Are Network Externalities a New Source of Market Failure,” Research in Law and Economics, 17: 1-22.

Liebowitz, S.J. and S.E. Margolis (1998) "Network Effects and Externalities," in P. Newman (ed.), The New Palgrave Dictionary of Economics and the Law, Vol. 2, Stockton Press: New York.

Liebowitz, S.J. and S.E. Margolis (2002) “Network Effects," in M. Cave, S. Majumdar, and I. Vogelsang (ed.), Handbook of Telecommunications Economics, Vol. 1, Elsevier: Amsterdam.

Matutes, C. and P. Regibeau (1988) “'Mix and Match': Product Compatibility Without Network Externalities,” RAND Journal of Economics, 19: 221-34.

Posner, R.A. (1998) Economic Analysis of Law, Fifth Edition. Aspen Law and Business: New York.

Rochet, J.-C., and J. Tirole (2003) "Platform Competition in Two-Sided Markets,” Journal of the European Economic Association, 1: 990-1029.

Rosen, R. (2005) “Two-Sided Markets: A Tentative Survey," Review of Network Economics 4: 142-160.

Spence, A.M. (1976) "Product Selection, Fixed Costs, and Monopolistic Competition," Review of Economic Studies, 43: 217-35. 


\section{$9 \quad$ Appendix}

In this appendix, we use the CES utility function and assume the software firms are monopolistic competitors. The utility function is

$$
U=x_{0}+Z-k t
$$

where $Z=\left(\sum_{i=1}^{N} x_{i}^{\frac{1}{\gamma}}\right)^{\gamma}, \gamma>1$, is the utility from the network, with $x_{i}$ the consumption of software variety $i$. Since the network component $Z$ is homogeneous of degree 1 , consumers spend either all of their income on the outside good $x_{0}$ or all on the network good.

Assume they spend it on $Z$, that is, an interior solution, then the demand function for a software variety is

$$
x_{i}=y q^{1 /(\gamma-1)} p_{i}^{\gamma /(1-\gamma)}
$$

where $p_{i}$ is the price of software variety $i$ and $q$ is the price index for the network good (assumed to be less than one for an interior solution). ${ }^{22}$ The price index is defined as

$$
q=\left[\sum_{i=1}^{N} p_{i}^{\frac{1}{(1-\gamma)}}\right]^{1-\gamma}
$$

If all software varieties are priced equally then (46) becomes

$$
q=N^{1-\gamma} p
$$

where $p$ is the common price of software. When all software varieties are priced the same, then (45) becomes

$$
x_{i}=x_{j}=x=\frac{y}{p N} .
$$

Substituting (48) into the utility function, indirect utility is

$$
V=\frac{y N^{\gamma-1}}{p}-k t
$$

To find $t$ use (49) and recognize that outside option yields utility of $y$

$$
\frac{y N^{\gamma-1}}{p}-k t=y
$$

or

\footnotetext{
${ }^{22}$ See Church and Gandal (1993) for derivation.
} 


$$
t_{m}=\frac{y\left[N^{\gamma-1}-p\right]}{p k} .
$$

Under monopolistic competition $p_{i}=p_{j}=p=\gamma s$, where $s$ is marginal cost. ${ }^{23}$ The free-entry number of software varieties is defined by the zero-profit condition

$$
(\gamma-1) s x t_{m}-f=0
$$

The social planner's objective function (second-best) is

$$
W=\int_{0}^{t_{s}}\left(\frac{y N^{\gamma-1}}{\gamma s}-k t_{s}\right) d t_{s}+\int_{t_{s}}^{1} y d t_{s},
$$

or after integrating

$$
W=\left(\frac{N^{\gamma-1}}{\gamma S}-1\right) y t_{s}-\frac{k t_{s}}{2}+y .
$$

So the CES equivalent of (37) in the paper is

$$
\frac{d W}{d t_{s}}=\left(\frac{N^{\gamma-1}}{\gamma S}-1\right) y+\frac{N^{\gamma-2}}{\gamma S}(\gamma-1) y t_{s} \frac{d N}{d t_{s}}-k t_{s} .
$$

Setting $d N / d t_{s}=0$ in (54) gives (51), recognizing that $p=\gamma s$.

The benefit from extra variety in the CES model is only from the variety effect since price and expenditure is independent of $N$. From (49)

$$
\frac{d V}{d N}=\frac{N^{\gamma-2}}{\gamma s}(\gamma-1) y
$$

which is the per capita marginal social benefit from increasing $N$ in (54).

\footnotetext{
${ }^{23}$ Again see Church and Gandal (1993) for derivation.
} 